\title{
Investigation of Various Nano-Structural Morphologies of Zinc Oxide for their Applications in Dye-Sensitized Solar Cells
}

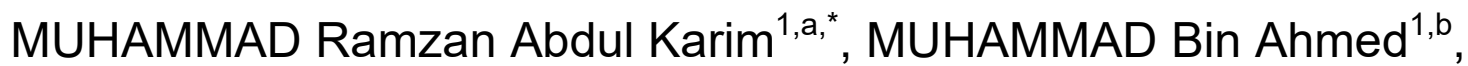 \\ EHSAN UI Haq ${ }^{2, \mathrm{c}}$, KHALID Mahmood ${ }^{3, \mathrm{~d}}$, AZHAR Hussain ${ }^{1, \mathrm{e}}$, \\ SULAIK Ullah Iqbal ${ }^{1, f}$, SYED Abrar Hussain Shah ${ }^{1, g}$, YASIR Faheem Joya ${ }^{1, h}$ \\ and AHMED Sher Awan ${ }^{4, i}$
}

${ }^{1}$ Faculty of Materials and Chemical Engineering, GIK Institute of Engineering Sciences and Technology, Topi-23640, Pakistan

${ }^{2}$ Department of Metallurgical and Materials Engineering, University of Engineering and Technology, Lahore-54890, Pakistan

${ }^{3}$ Department of Chemical \& Polymer Engineering (FSD Campus), University of Engineering and Technology, Lahore, Pakistan

${ }^{4}$ Institute of Education and Research, University of the Punjab, Lahore, Pakistan

aramzan.karim@giki.edu.pk, 'bmbathegreat1994@gmail.com, camonehsan@hotmail.com,

dkm_engr@hotmail.com, eazharhussain1150@hotmail.com, 'sulaikullahiqbal@gmail.com,

gbukhari371@gmail.com, hyasir.joya@giki.edu.pk, 'a.sherawan@yahoo.com.

Keywords: Zinc oxide, Dye-sensitized solar cell, Nanostructures, Semiconductor, Surface area, Light-scattering, Hydrothermal growth

\begin{abstract}
In the current study, various morphologies of zinc oxide $(\mathrm{ZnO})$ including nano-rods, nano-flowers, nano-sheets/flakes, nano-spherical particles, nano-hexagonal sheets, and nanoneedles have been prepared by using single step and two-step hydrothermal processes with optimized parameters such as growth temperature, growth time and compositions of both the seed and growth solutions. Fluorine doped tin oxide (FTO) coated glass was used as the substrate. The prepared morphologies were characterized with the help of scanning electron microscopy (SEM) and the purity of nanostructures was confirmed by elemental analysis (EDX). These nanostructures were used as photo-anode material to fabricate the DSSC using a dye (Rhodamine B) for enhancing the range of solar spectrum that is to be adsorbed. Finally, the fabricated solar cells were characterized in terms of their efficiency, gauged by their fill factor. Among different morphologies investigated as photo anode materials; nano-sheets/flakes were found to be showing maximum efficiency, with fill factor values around 0.5 due to their larger surface area, better porosity and enhanced capability of light trapping and scattering.
\end{abstract}

\section{Introduction}

For past few years, many semiconducting materials including non-oxides and metals oxides are being used as an alternative to conventional silicon based semiconducting materials [1]. Specifically zinc oxide $(\mathrm{ZnO})$ has been most attractive for photonics and electronics devices because of its high conductivity and its abundance in nature [2]. Some of its applications in different fields of electronics include the devices used in surface acoustic wave, sensors, UV lasers, field emitters and cells [3]. It has wide band gap of $3.37 \mathrm{eV}$ and high bond strength of $60 \mathrm{meV}$ at ambient conditions [4]. So $\mathrm{ZnO}$ is a promising candidate as a low-cost porous semiconductor material and has been investigated as photo anode in dye-sensitized solar cells (DSSCs) [5-6]. In order to be used in dyesensitized-solar cells (DSSCs), ZnO is required to achieve higher efficiency. The DSSCs based on nanostructured $\mathrm{ZnO}$ exhibit the prominent efficiency compared to $\mathrm{ZnO}$ thin films based solar cells owing to their larger surface area, better light harvesting and scattering abilities [7].

A cutting edge DSSC is made out of a permeable layer of oxide semi-conductor nanoparticles, secured with a sub-atomic color that retains daylight, similar to the chlorophyll. Semi-conductor is 
drenched in an electrolyte arrangement. An anode (oxide semi-conductor) and a cathode, counter terminal are set on either side of a fluid conductor (the electrolyte) [8]. Its flexible constants are more diminutive than those of vital III-V semiconductors, for instance, GaN. The high warmth farthest point and warmth conductivity, low warm improvement and high dissolving temperature of $\mathrm{ZnO}$ are profitable for ceramics [9].

Various methods have been used for the manufacturing of different types of solar cells. For example, crystalline Si-cells are made from most commonly used industrial process called the Czochralski method [10]. Amorphous Si-cells are made from radio frequency plasma enhanced chemical vapor deposition process (RFPECVD) [11]. Thin film cell technologies include deposition of absorbent layer on to a conducting substrate where the thickness of the deposits is in the range of few tens of micron [12]. Solar cells are also being made by growing nanostructures onto the substrates via hydrothermal synthesis [13]. Among all the techniques, hydrothermal method is the easiest, simple, economical and fast approach [14].

In hydrothermal methods, the parameters like working temperature, pressure and solution composition, influence the type and morphology of resulting nanostructures [15]. Among various advantages of hydrothermal method include the cost effective development of different sorts of crystal structures, capacity to make crystalline stages which are not steady at the melting point and the nano-strucural growth of materials having high vapor pressures close to their softening points [16]. One of the drawback of hydrothermal technique is the impossibility of watching the growing crystals during structure development [17].

In this work, this simple and easy hydrothermal method was used for growing $\mathrm{ZnO}$ nanostructures with two variants; single step hydrothermal synthesis and two step hydrothermal synthesis. Various structural morphologies of zinc oxide like nano-flowers, nano-flakes, nanohexagonal sheets, spherical particles and rod and needle type morphologies were prepared by varying the experimental conditions. The resulting structures were characterized by SEM, EDX and I-V characteristic curves verify the results.

\section{Materials and Methods}

Materials. Zinc nitrate, zinc acetate, hexamethylenetetramine (HMTA), ethanol, citric acid, starch, ammonium hydroxide were purchased from Sigma-Aldrich. All the chemicals were of analytical grade and high purity. Fluorine doped tin oxide (FTO) glass substrates were purchased from Xin Yan Technology LTD Hong Kong having dimensions of $20 \mathrm{~mm}$ x $20 \mathrm{~mm}$ x $2.2 \mathrm{~mm}$ and sheet resistance of $15 \mathrm{ohm} / \mathrm{sq}$. The solution of commercially and locally available Rhodamine $\mathrm{B}$ $\left(\mathrm{C}_{28} \mathrm{H}_{31} \mathrm{ClN}_{2} \mathrm{O}_{3}\right)$ was used as sensitizing dye.

Synthesis of Zinc Oxide Nano-Structures. Two different types of hydrothermal procedures were used for the synthesis of different morphologies of zinc oxide nano-structures; (a) single step hydrothermal process and (b) two step hydrothermal process.

Single Step Hydrothermal Process. In this process hydrothermal reaction was carried out in a single step inside a steel autoclave whose schematic diagram is shown in Fig. 1.

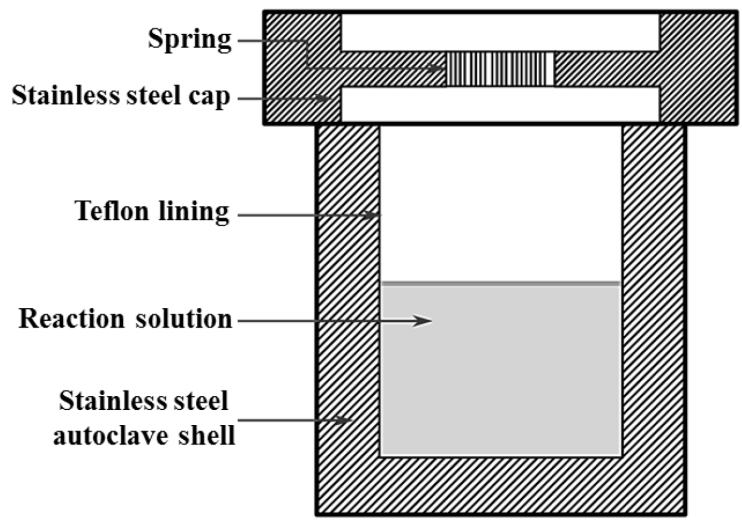

Fig. 1 Schematic of an autoclave reactor. 
Zinc nitrate was dissolved in distilled water with different compositions and addition of different surfactants like HMTA here after referred to as Experiment H, starch as Experiment S, citric acid as Experiment $\mathrm{C}$, and experiment with no surfactants as Experiment P. Solution was stirred by using magnetic stirrer until the formation of homogeneous solution. After that, dilute solution of ammonium hydroxide (10\%) was added drop wise to produce the following reactions:

$$
\begin{aligned}
& \mathrm{ZnNO}_{3}(\mathrm{aq})+2 \mathrm{NH}_{4} \mathrm{OH}(\mathrm{aq}) \rightarrow \mathrm{Zn}(\mathrm{OH})_{2}(\mathrm{~s})+2 \mathrm{NH}_{4} \mathrm{NO}_{3}(\mathrm{aq}) \\
& \mathrm{Zn}^{2+}(\mathrm{aq})+\mathrm{OH}^{-}(\mathrm{aq}) \rightarrow \mathrm{Zn}(\mathrm{OH})_{2}(\mathrm{~s}) \\
& \mathrm{Zn}^{2+}+2 \mathrm{OH}^{-} \rightarrow \mathrm{ZnO}+\mathrm{H}_{2} \mathrm{O}
\end{aligned}
$$

After maintaining $\mathrm{pH}$ of the solution the solution in the autoclave at a fixed temperature a thermocouple was used to monitor the temperature. Reaction was carried out at autogenously maintained pressure being observed by a pressure gauge attached to autoclave. At that much pressure and temperature $\mathrm{Zn}(\mathrm{OH})_{2}$ (s) dissociates into $\mathrm{ZnO}$ particles and $\mathrm{H}_{2} \mathrm{O}$ due to thermal degradation.

After each experiment the produced material was filtered and then dried in an oven at $80{ }^{\circ} \mathrm{C}$. Then the product of each experiment was suspended in $0.05 \mathrm{wt}$. \% solution of polyethylene glycol (PEG). The details of the single step hydrothermal experiments are shown in Table 1.

Table 1 Conditions used for the single step hydrothermal experiments

\begin{tabular}{cccccccc}
\hline Experiments & Additive & $\begin{array}{c}\text { Weight of } \\
\mathbf{Z n}\left(\mathbf{N O}_{3}\right)_{2} \\
{[\mathbf{g}]}\end{array}$ & $\begin{array}{c}\text { Temp. } \\
{\left[{ }^{\circ} \mathbf{C}\right]}\end{array}$ & $\mathbf{p H}$ & $\begin{array}{c}\text { Time } \\
{[\mathbf{m i n}]}\end{array}$ & $\begin{array}{c}\text { Pressure } \\
{[\mathbf{p s i}]}\end{array}$ & $\begin{array}{c}\text { Solution } \\
{[\mathbf{m L}]}\end{array}$ \\
\hline $\mathrm{P}$ & - & 0.5 & 70 & 7.1 & 12 & 5 & 50 \\
$\mathrm{H}$ & HMTA & 1.0 & 80 & 8.6 & 120 & 3 & 100 \\
$\mathrm{~S}$ & Starch & 1.0 & 150 & 8.0 & 90 & 26 & 100 \\
$\mathrm{C}$ & Citric & 1.0 & 150 & 6.5 & 120 & 29 & 100 \\
\hline
\end{tabular}

Two Step Hydrothermal Process. In the two step hydrothermal process first $0.05 \mathrm{M} \mathrm{ZnO}$ seed solutions (SS) were prepared with three different compositions; in $50 \mathrm{~mL}$ ethanol, in $50 \mathrm{~mL}$ ethanol plus deionized water with 1:1 ratio, and in $50 \mathrm{~mL}$ of deionized water, were prepared. Then, from these seed solutions, seed layers were spin coated on the FTO glass substrates with $2500 \mathrm{rpm}$ for three minutes, followed by drying at $100{ }^{\circ} \mathrm{C}$ for five minutes. Table 2 summarizes the used compositions of the seed layers along with spin coating and drying parameters.

Table 2 Compositions of different seed solutions (SS) used for two step hydrothermal process

\begin{tabular}{cccccccccc}
\hline Solution & $\begin{array}{c}\text { Composition } \\
\text { deionized } \\
\text { water/ethanol }\end{array}$ & $\begin{array}{l}\text { Spin coating } \\
{[\mathbf{r p m}]}\end{array}$ & \multicolumn{1}{c}{ Drying } & & Growth & \multicolumn{2}{c}{ Calcination } \\
\cline { 4 - 8 } & & $\begin{array}{l}\text { Temp. } \\
{\left[{ }^{\circ} \mathbf{C}\right]}\end{array}$ & $\begin{array}{l}\text { Time } \\
{[\mathbf{m i n}]}\end{array}$ & $\begin{array}{l}\text { Temp. } \\
{\left[{ }^{\circ} \mathbf{C}\right]}\end{array}$ & $\begin{array}{l}\text { Time } \\
{[\mathbf{m i n}]}\end{array}$ & $\begin{array}{l}\text { Temp. } \\
{\left[{ }^{\circ} \mathbf{C}\right]}\end{array}$ & $\begin{array}{c}\text { Time } \\
{[\mathbf{m i n}]}\end{array}$ \\
\hline SS 1 & $0 / 50 \mathrm{~mL}$ & 2500 & 100 & 5 & 60 & 5 & 260 & 20 \\
SS 2 & $25 / 25 \mathrm{~mL}$ & 2500 & 100 & 5 & 60 & 5 & 260 & 20 \\
SS 3 & $50 / 0 \mathrm{~mL}$ & 2500 & 100 & 5 & 60 & 5 & 260 & 20 \\
\hline
\end{tabular}

At the second step solutions of $0.05 \mathrm{M}$ zinc nitrate and $0.05 \mathrm{M}$ HMTA were prepared and mixed to make a growth solution. The FTO substrate coated with different seed solutions were placed in the growth solution contained in beakers. The beakers were then placed in an oven at $60{ }^{\circ} \mathrm{C}$ for 1 hour at autogenous pressure to assist the hydrothermal growth of various nano-structural 
morphologies of $\mathrm{ZnO}$. Then the substrates with nanostructures grown on them were taken out from the solution and calcined at $260{ }^{\circ} \mathrm{C}$ for 20 minutes. The following reactions occur during the whole process of synthesis.

$$
\begin{aligned}
& \mathrm{Zn}\left(\mathrm{O}_{2} \mathrm{CCH}_{3}\right)_{2}+\mathrm{C}_{2} \mathrm{H}_{6} \mathrm{O}+\mathrm{H}_{2} \mathrm{O} \rightarrow \mathrm{Zn}(\mathrm{OH})_{2}+\mathrm{CH}_{3}-\mathrm{COO}-\mathrm{CH}_{2}-\mathrm{CH}_{3} \\
& \mathrm{Zn}(\mathrm{OH})_{2} \rightarrow \mathrm{Zn}^{2+}+2 \mathrm{OH}^{-} \\
& \mathrm{Zn}^{2+}+2 \mathrm{OH}^{-} \rightarrow \mathrm{ZnO}+\mathrm{H}_{2} \mathrm{O}
\end{aligned}
$$

Fabrication of Dye Sensitized Solar Cell (DSSC). A DSSC assembly consists of a semi-conductor coated electrode, a counter electrode, sensitizing element dye and an electrolyte solution. FTO glass substrates coated with carbon black was used as counter electrode. Silver nitrate solution $(0.01 \mathrm{M})$ was used as the electrolyte, the FTO glass substrates with grown nanostructures acted as the semiconductor anodes. The solution of commercially available Rhodamine $\mathrm{B}\left(\mathrm{C}_{28} \mathrm{H}_{31} \mathrm{ClN}_{2} \mathrm{O}_{3}\right)$ dye was used to make the semiconductor anode material photo sensitive. In the DSSC, a bulk amount of the semiconductor is utilized exclusively for charge transport, the photoelectrons are given from a different photosensitive dye. Charge partition happens at the surfaces between the dye, semiconductor and electrolyte [8].

I-V characteristics. I-V characteristics of the fabricated DSSCs were determined by using LSH7520 AAA solar simulator to calculate the fill factor $(F F)$. The $F F$ is defined as the ratio of the maximum power from the solar cell to the product of $\mathrm{V}_{\mathrm{oc}}$ and $\mathrm{I}_{\mathrm{sc}}$ and is given by Eq. 7 [18].

$$
F F=\frac{V_{M P} I_{M P}}{V_{O C} I_{S C}}
$$

The short-circuit current $\left(\mathrm{I}_{\mathrm{sc}}\right)$ and the open-circuit voltage $\left(\mathrm{V}_{\mathrm{oc}}\right)$ are the maximum current and voltage respectively from a solar cell.

\section{Results and Discussions}

In single step hydrothermal process different morphologies of Zinc Oxide crystals were obtained by varying the composition, temperature, $\mathrm{pH}$, and time for the reaction in hydrothermal reactor. In experiment P (with no addition, "Pure") spherical particles of zinc oxide were obtained. These particles agglomerated to form a sponge like structure, as shown in Fig. 2 (left). The EDX spectra in the Fig. 2 (right) confirms the presence of $\mathrm{Zn}$ and $\mathrm{O}$. A peak of $\mathrm{Al}$ is also detected which is possibly from the aluminum stub used as sample holder.
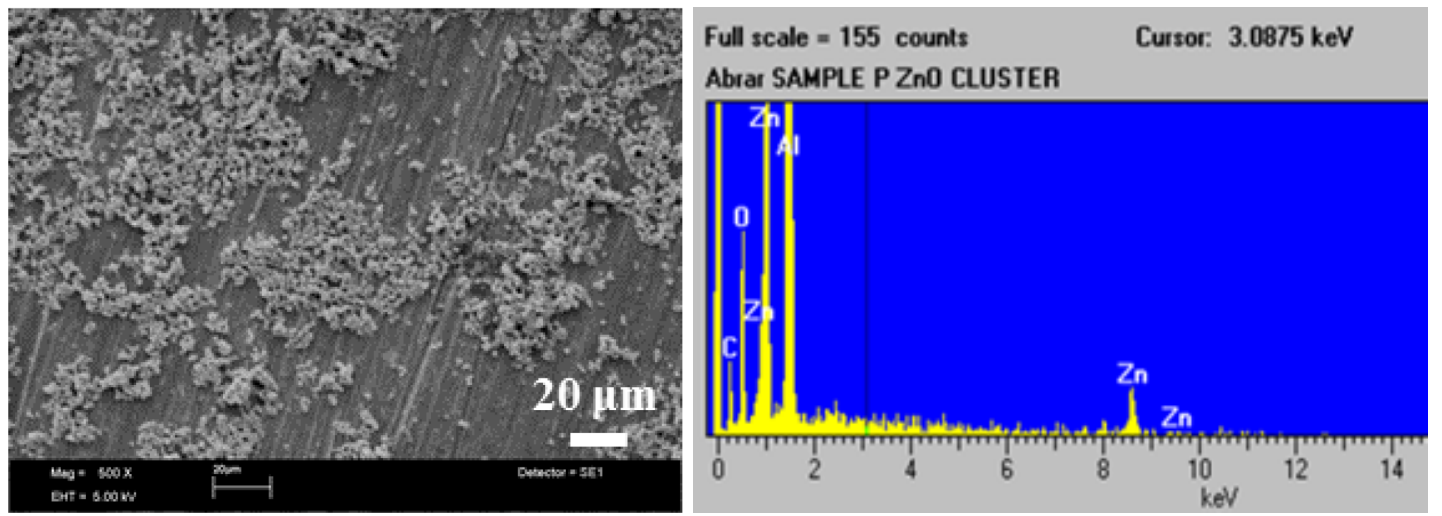

Fig. 2 SEM image of Experiment P (left) showing agglomerated spherical particles and EDX spectra (right) confirming the presence of $\mathrm{ZnO}$. 
In experiment $\mathrm{H}$ (with addition of HMTA) flower like morphology of $\mathrm{ZnO}$ was obtained as shown in Fig. 3. The observation of Fig. 3 suggested that this flower like morphology is obtained via passing through nucleation and growth stages.
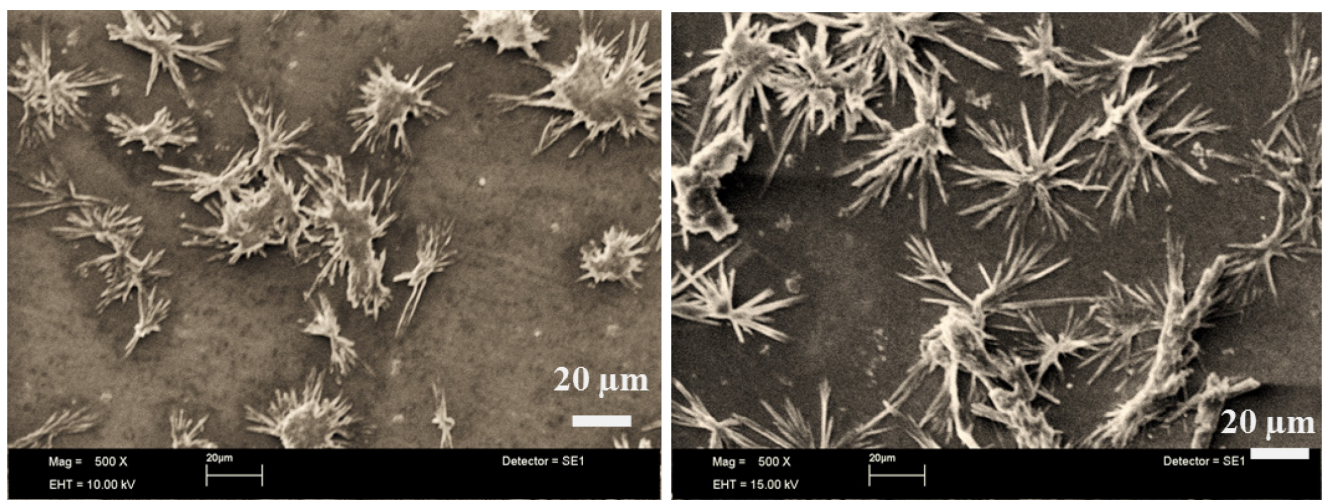

Fig. 3 SEM images of Experiment H showing nucleation (left) and growth (right) of flower-like morphology

In experiment $\mathrm{S}$ (with addition of starch) zinc oxide spherical particles with a better dispersion were formed. Some particles agglomerate and result in the formation of clusters, as shown in Fig. 4 (left). The presence of peaks of Al and Au in EDX spectra shown in Fig. 4 (right) are due to the use of aluminum stub and gold sputtering. In experiment $\mathrm{C}$ (with addition of citric acid) needle like morphology of zinc oxide was observed. From SEM micrographs it can be observed that these needles are not perfectly along Z-axis, as shown in Fig. 5 (left). This is because no preferred nucleation sites were provided for the growth of needles. In these type of experiments too, the presence of $\mathrm{ZnO}$ is confirmed by the EDX analysis presented in Fig. 4 (right) and Fig. 5 (right).
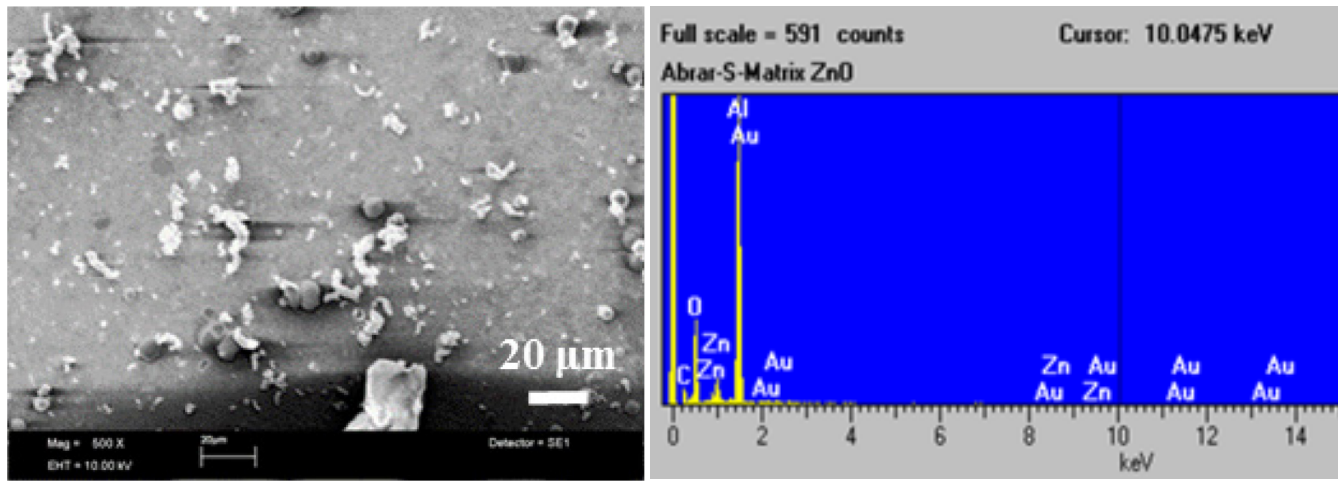

Fig. 4 SEM image (left) of Experiment $\mathrm{S}$ showing spherical particles with less agglomeration, and EDX spectra (right) confirming the presence of $\mathrm{ZnO}$.
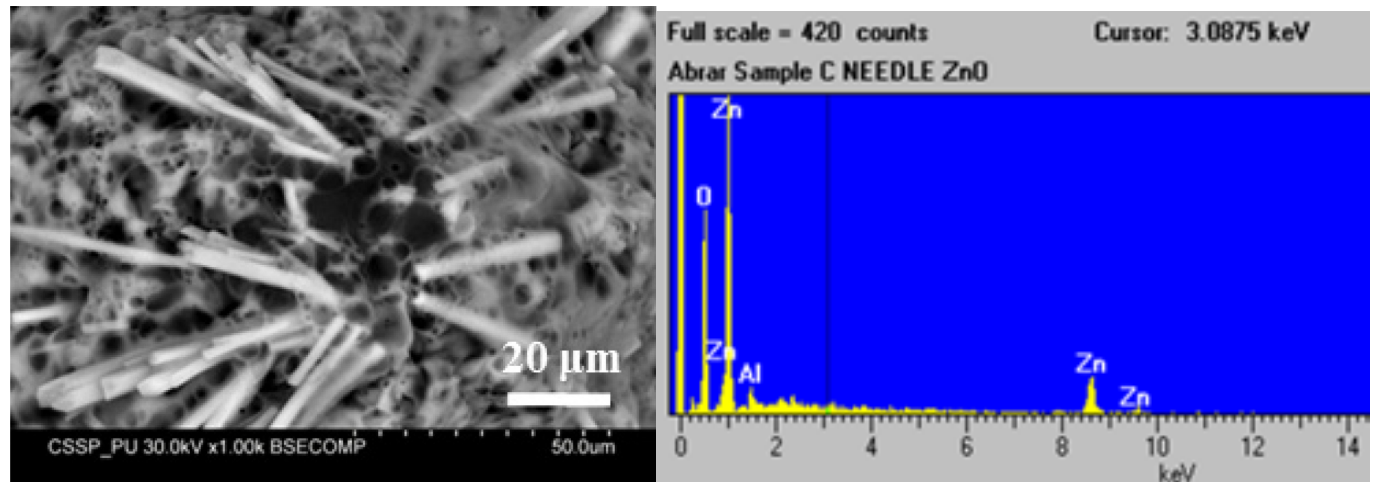

Fig. 5 (a) SEM image (left) of Experiment $\mathrm{C}$ showing needle-type morphology in $\mathrm{ZnO}$ crystals, and EDX spectra (right) confirming the presence of $\mathrm{ZnO}$. 
In two step hydrothermal process by using seed solution 1, rod-type morphology of zinc oxide was observed. Some of the rods were converted in to block type morphology due to extensive growth. Since the rods are not perfectly aligned along z-axis, as shown in Fig. 6, so these cannot be used to make an efficient DSSC.

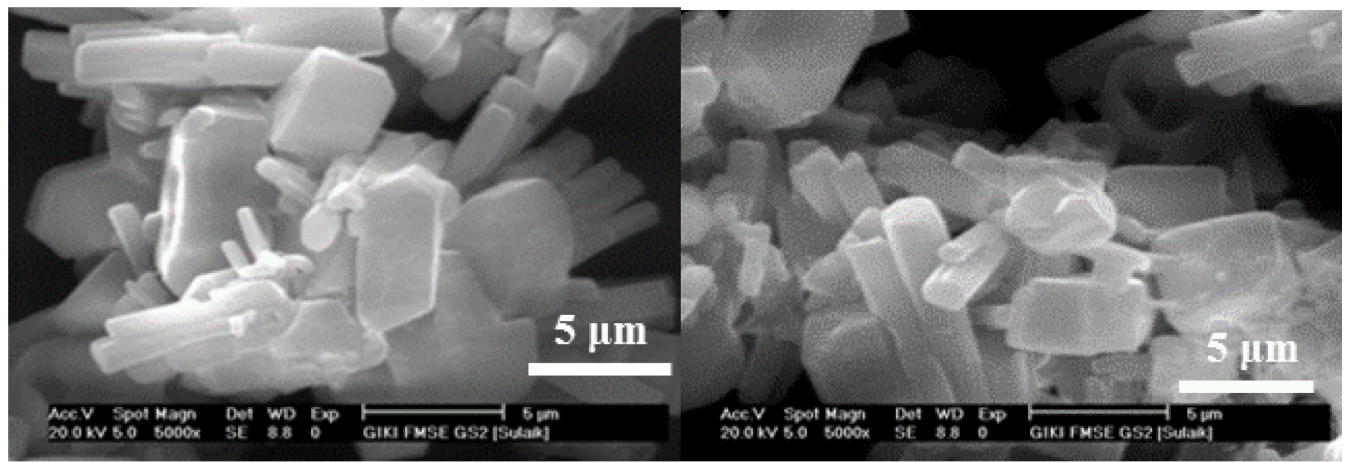

Fig. 6 SEM images of rod-type $\mathrm{ZnO}$ from Seed solution 1.

By using seed solution 2, zinc oxide nano-flakes/nano-sheets were obtained, as shown in Fig. 7. Average thickness of these nano-sheets was measured to about $250 \mathrm{~nm}$. Theses sheets are intersecting each other and have high porosity. These SEM images also show a homogeneous layer of nano-sheets deposited on substrate. These structures have various advantages of usage in fabrication of a dye sensitized solar cell. Because of their high surface area and surface energy, an increased contact area with electrolyte is achieved that results in an easy transfer of the charges. It also helps the semi-conductor material to harvest a large amount of solar light by scattering of incident light inside the solar cell which leads to increased conversion efficiency of dye sensitized solar cell.

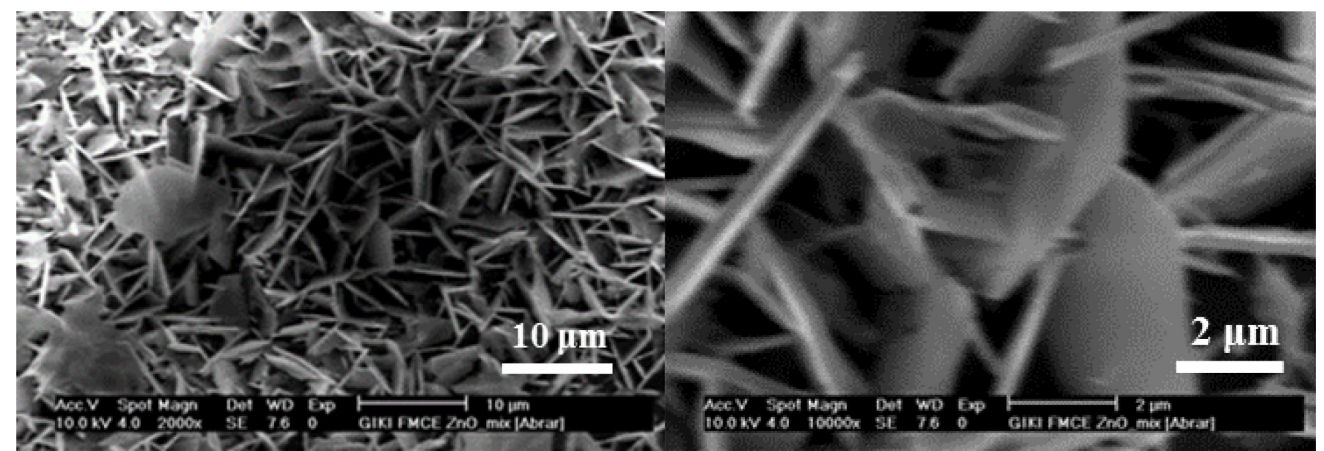

Fig. 7 SEM images $\mathrm{ZnO}$ nano-flakes obtained from Seed solution 2 at different magnifications.

By using seed solution 3, hexagonal transparent sheets of zinc oxide were obtained, as shown in Fig. 8 (left). These sheets are transparent to the extent that the sheet below these sheets can be easily seen. Although they have high surface area and energy but sheets are lying along horizontal axis with one face not exposed to incident light. This also increases the resistance for the charge transfer [19], as a result conversion efficiency of DSSC decreases. EDX analysis of samples obtained by using two step hydrothermal process is shown in Fig. 8 (right). The peak for $\mathrm{Cl}$ has possibly come from $\mathrm{HCl}$ added to the $\mathrm{ZnO}$ seed layer solution to dissolve the remaining residual salts and get the clear solution [20], as mentioned in the experimental section too.

The morphologies with the nano-rods, nano-flakes and nano-hexagonal sheets (prepared by two step hydrothermal process) were evaluated for their I-V characteristics. Finally, the fill factor was calculated in order to evaluate the efficiency of different morphologies. I-V characteristic curves in Fig. 9 suggest that size, shape and morphology of zinc oxide affect the conversion efficiency of DSSCs.

Table 3 shows that DSSCs with nano-flakes and nano-rods have larger fill factors than the nanohexagonal sheets. This is because 1D nano-flakes and nano-rods are believed to have higher surface area (surface to volume ratio) and better charge transfer and carrier mobility [21,22]. It results in an 
increased contact area of electrolyte with semi-conductor and making the electron transfer easier between anode and cathode. Their random orientation helps them to harvest a large amount of solar energy by increasing the scattering of photons between the empty spaces of nano-flakes resulting in the increased number electrons and consequently the fill factor and conversion efficiency [22].
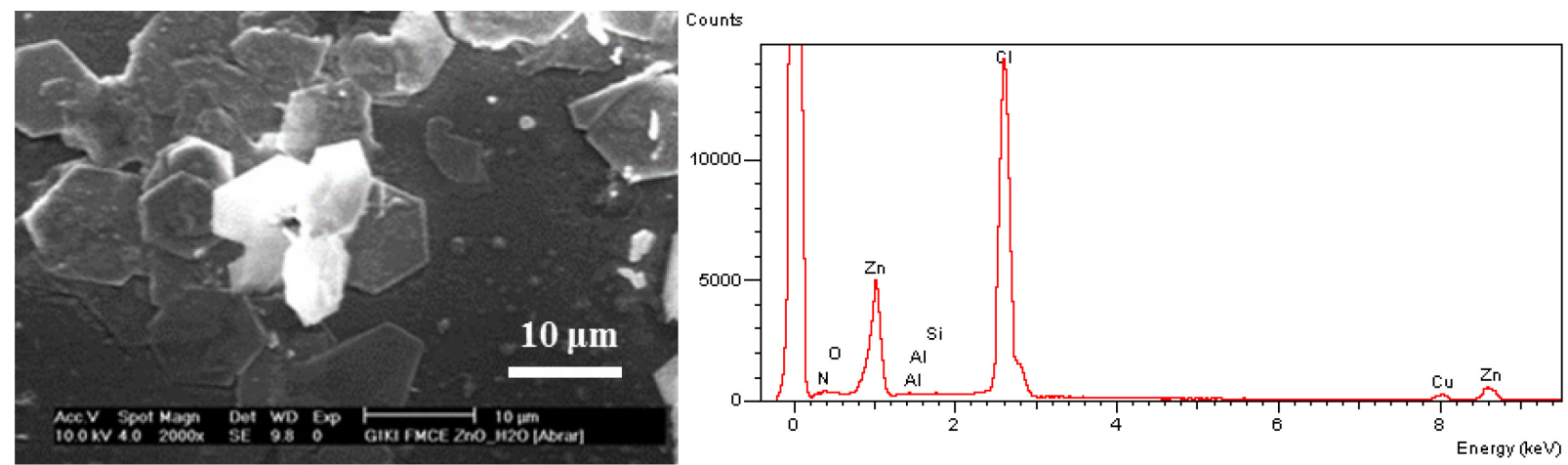

Fig. 8 SEM image (left) of hexagonal $\mathrm{ZnO}$ sheets obtained from seed solution 3 and EDX analysis (right) confirming the presence of $\mathrm{ZnO}$.

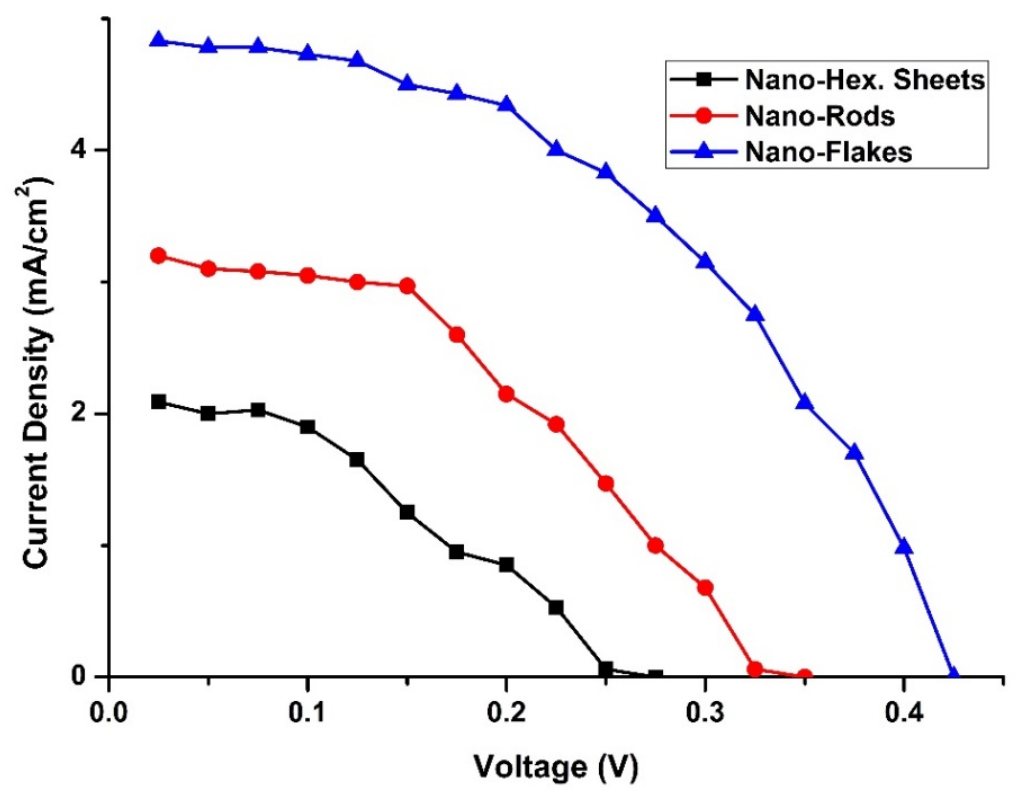

Fig. 9 I-V curves for DSSCs based on different morphologies of $\mathrm{ZnO}$.

Table 3 Fill Factor calculations of DSSCs with various nano-structural morphologies of $\mathrm{ZnO}$

\begin{tabular}{llllll}
\hline Structural morphology & $\begin{array}{l}\mathrm{V}_{\mathrm{OC}} \\
{[\mathrm{V}]}\end{array}$ & $\begin{array}{l}\mathrm{V}_{\mathrm{MP}} \\
{[\mathrm{V}]}\end{array}$ & $\begin{array}{l}\mathrm{I}_{\mathrm{SC}} \\
{[\mathrm{mA}]}\end{array}$ & $\begin{array}{l}\mathrm{I}_{\mathrm{MP}} \\
{[\mathrm{mA}]}\end{array}$ & $\mathrm{FF}$ \\
\hline Nano-flakes/sheets & 0.425 & 0.275 & 31.41 & 24.58 & 0.46 \\
Nano-rods & 0.35 & 0.2 & 20.7 & 13.87 & 0.38 \\
Nano-hexagonal sheets & 0.3 & 0.175 & 13.5 & 5.8 & 0.25 \\
\hline
\end{tabular}

\section{Conclusions}

Nanostructures with different morphologies such as nano-flowers, nano-flakes, nano-hexagonal sheets, spherical particles, nano-rods and needles of zinc oxide $(\mathrm{ZnO})$ have been successfully prepared by using simple and viable hydrothermal method. The different nanostructures are resulted by different experimental parameters such as concentration, composition, temperature, $\mathrm{pH}$ and pressure. Also the single step and two step approaches give rise to the formation of different morphologies. Among different morphologies investigated as photo anode materials, nano-flakes and nano-rods were found to be showing higher efficiency, gauged in terms of their fill factor, than the hexagonal nano-sheets due to their enhanced light trapping and scattering capability. 


\section{References}

[1] S. Lee, S. Yang, H. Yun, K. Jeong, Y. Kim, S. Kim, H. Lee, G. Lee and J. Oh, Pillar Type Silicon-Oxide-Nitride-Oxide-Silicon Flash Memory Cells with Modulated Tunneling Oxide, Trans. Electr. Electron. Mater., 14 (2013) 250-253.

[2] D. Li, J. She, S. Xu and S. Deng, Zinc Oxide Nanowire Lateral Field Emission Devices and its Application as Display Pixel Structures, IEEE Trans. Elect. Dev., 60 (2013) 2924-2930.

[3] M. Wang, Y. Wang and J. Li, ZnO nanowire arrays coating on $\mathrm{TiO} 2$ nanoparticles as a composite photoanode for a high efficiency DSSC, Chem. Commun., 47 (2011) 11246-11248.

[4] H. Waqas, M. Salman, A. Riaz, N. Riaz and S. Shabbir, Unique morphologies of zinc oxide synthesized by thermal decomposition and co-precipitation routes: Ultraviolet absorption and luminescence characteristics, Cryst. Res. Technol., 50 (2015) 379-388.

[5] K. Mahmood and S. Park, Growth and conductivity enhancement of N-doped ZnO nanorod arrays, J. Cryst., Growth 347 (2012) 104-112.

[6] N. Rana, S. Chand and A. Gathania, Band gap engineering of $\mathrm{ZnO}$ by doping with Mg, Phys. Scr., 90 (2015) 085502.

[7] C. Kung, S. Young and M. Kao, Thickness effect of sputtered $\mathrm{ZnO}$ seed layer on the electrical properties of Li-doped $\mathrm{ZnO}$ nanorods and application on the UV photodetector, IEEE 5th International Nanoelectronics Conference (INEC) Singapore, (2013) 417-420.

[8] M. Kim and Y. Kwon, Semiconductor CdO as a Blocking Layer Material on DSSC Electrode: Mechanism and Application, J. Phys. Chem. C, 113 (2009) 17176-17182.

[9] J. LaForge and M. Brett, Fabrication of Highly Porous Zinc and Zinc Oxide Nanostructures, Materials Research Society Proceedings (2008) 1142-JJ05-37.

[10] T. Mchedlidze and J. Weber, Radial distribution of iron in silicon crystals grown by Czochralski method from contaminated feedstock, Phys. Status Solidi RRL 8 - Rap. Res. Lett., 3 (2014) 228-230.

[11] A. Ahnood, Y. Suzuki, A. Madan and A. Nathan, Pulsed-radio frequency plasma enhanced chemical vapour deposition of low temperature silicon nitride for thin film transistors, Th. Sol. Fil., 520 (2012) 4831-4834.

[12] K. Yamamoto, Key Technologies for Next Generation Thin Film Silicon Solar Cells. Thin Film Si Solar Cell Fabricated at Low Temperatures, Hyom. Kaga., 21 (200) 272-277.

[13] W. Q.Wu, B. X. Lei, , H. S. Rao, Y. F. Xu, Y. F. Wang, C. Y. Su, and D. B. Kuang, Hydrothermal Fabrication of Hierarchically Anatase $\mathrm{TiO}_{2}$ Nanowire Arrays on FTO Glass for Dye-Sensitized Solar Cells, Scient. Rep., 3 (2013) 1352.

[14] N. Asim, S. Ahmadi, M. A. Alghoul, F. Y. Hammadi, K. Saeedfar and K. Sopian1, Research and development aspects on chemical preparation techniques of photoanodes for dye sensitized solar cells, Internat. J. Photoener., (2014) 518156.

[15] C. Yoon and S. Kang, Synthesis of $\mathrm{Zn} 2-\mathrm{xMn} x \mathrm{SiO} 4$ phosphors using a hydrothermal technique, J. Mater. Res., 16, (2001) 1210-1216.

[16] S. Denchitcharoen, N. Siriphongsapak and P. Limsuwan, Growth of ZnO nanosheets by hydrothermal method on $\mathrm{ZnO}$ seed layer coated by spin-coating technique, Materials Today: Proceedings 4, (2017) 6146-6152.

[17] K. Byrappa and M. Yoshimura, Handbook of hydrothermal technology, second ed., William Andrew Publishing, Oxford, 2013. 
[18] V. Georgieva, A. Tanusevski and M. Georgieva, Low Cost Solar Cells Based on Cuprous Oxide, in Prof. L. A. Kosyachenko (Ed.), Thin-Film Technologies, INTECH Open Access Publisher, 2011.

[19] K. Mahmood and S. Park, Highly efficient dye-sensitized solar cell with an electrostatic spray deposited upright-standing boron-doped $\mathrm{ZnO}$ (BZO) nanoporous nanosheet-based photoanode, J. Mater. Chem. A, 1 (2013) 4826-4835.

[20] K. Mahmood, D. Song and S. Park, Effects of thermal treatment on the characteristics of boron and tantalum-doped $\mathrm{ZnO}$ thin films deposited by the electrospraying method at atmospheric pressure, Surf. Coat. Technol., 206 (2012) 4730-4740.

[21] S. Duo, Y. Li, Z. Liu, R. Zhong, T. Liu, H. Xu, Preparation of ZnO from 2 D nanosheets to diverse $1 \mathrm{D}$ nanorods and their structure, surface area, photocurrent, optical and photocatalytic properties by simple hydrothermal synthesis, J. Alloys Compd., 695 (2017) 2563-2579.

[22] K. Mahmood, H.W. Kang, R. Munir and H.J. Sung, A dual-functional double-layer film with indium-doped $\mathrm{ZnO}$ nanosheets/nanoparticles structured photoanodes for dye-sensitized solar cells, RSC Adv., 3 (2013) 25136-25144. 